\title{
Attitudes concerning crimes related to clothing worn by female victims
}

\author{
ED M. EDMONDS and DELWIN D. CAHOON \\ Augusta College, Augusta, Georgia
}

\begin{abstract}
Male and female college students were shown one of two slides featuring a female model wearing either sexy or nonsexy clothes. The subjects were then asked to answer a set of questions based upon the supposition that the model might be either robbed or raped. Responses indicated that the model wearing sexually oriented clothes was seen as more likely to be either robbed or raped, more likely to provoke such an attack, and more likely to be responsible for the attack if she were to be assaulted. Furthermore, the model's assailant was held to be less accountable if the model was assaulted while wearing sexy clothes than while wearing sexually conservative clothes. The results are discussed with respect to attribution theory and the literature concerning crimes against women, particularly rape.
\end{abstract}

Rape is the most rapidly increasing crime in American society. The National Crime Survey (1984) estimates that during the interval 1973-1982 there were about 1.5 million rapes or attempted rapes in the United States. Since many rapes are not reported to the police, the actual frequency of sexual assaults is no doubt much higher.

Most of the studies concerning variables related to rape have focused upon males. Malamuth (1986), for example, has developed a regression equation predictive of male sexual aggression based upon sexual arousal in response to aggression, dominance as a motive for sexual acts, hostility toward women, attitudes accepting violence against women, psychotism, and sexual experience. Furthermore, there is evidence that, just as some males are more likely than others to commit rape, some females are more likely than others to be victims of rape. Variables so far described include marital status (Feldman-Summers \& Lindner, 1976; Jones \& Aronson, 1973), social role (Smith, Keating, Hester, \& Mitchell, 1976), history of prior rapes (Calhoun, Selby, \& Warring, 1976), and extent of acquaintance with the rapist (Calhoun et al., 1976; Smith et al., 1976). The relationship between the physical attractiveness of the victim and the perceived likelihood of rape has also been examined. Seligman, Brickman, and Koulack (1977) found that although attractive females were judged more likely to be raped, nonattractive victims were seen as more responsible for the assault, a finding also supported by Tieger (1981). In general, these studies tend to support an attribution theory analysis (Kelley, 1971); that is, since nonattractive females are seen as less likely to be raped than attractive females, nonattractive women are perceived as relatively more likely to have provoked the attack.

Most of the studies examining female correlates of rape have not controlled for the possibility that certain women may be perceived as more vulnerable to criminal assaults

Reprint requests may be sent to Ed M. Edmonds, Department of Psychology, Augusta College, Augusta, GA 30910. in general. That is, although physical appearance, for example, is related to perceptions of rape likelihood, it is not known whether this correlation is specific only to sexual assault. It is equally possible that attractive females are viewed as more vulnerable to assault in general, including such nonsexual crimes as mugging and robbery. The present investigation examines the relationship between two types of clothing worn by females and the perceived likelihood of sexual assault. In addition, the clothing styles are similarly related to the perceived likelihood that the female might be subject to the apparently nonsexual crime of robbery.

\section{METHOD}

\section{Subjects}

The subjects were 52 males and 91 females recruited from introductory psychology classes at Augusta College. No special incentive for participating in the experiment was offered. Males and females were assigned to four groups (two male and two female) corresponding to four experimental conditions described below. The study was conducted in a classroom setting with only the subjects from one subgroup and the examiner present. All subjects were assured that their responses would be treated as confidential.

\section{Procedure}

Two slides were prepared for the study featuring a college-age Caucasian female wearing two styles of clothing. On one slide, the model wore slacks and a blouse that might be termed attractive but conservative. The other slide depicted the model in a dress that revealed breasts and legs to a greater extent. A pilot investigation revealed no differences in ratings of the clothing styles with the model's face obscured or with the photograph unaltered. Both slides were therefore cropped at neck level in order to avoid possible contamination related to facial expression or recognition of the model. The same model was shown in both slides and, insofar as possible, poses were similar. Subjects were shown one of the two slides and given a questionnaire to complete based upon that slide. The questionnaire forms were also of two varieties. One form presented the model as possibly being robbed, whereas a second form asked the rater to assume that the model might be raped. All questionnaires contained the same set of eight items requiring the subject to rate (on a 5-point scale) opinions concerning the female depicted in the slide. The experimental design can thus be summarized as a $2 \times$ 
$2 \times 2$ factorial design (male-female raters $\times$ sexy-nonsexy clothing $\times$ robbery-rape premise).

\section{RESULTS AND DISCUSSION}

Responses to the eight questions were analyzed with respect to (1) the sex of the rater, (2) the clothing style (sexy or nonsexy) depicted in the slide, and (3) the type of crime (robbery or rape) to be considered. The mean ratings (5-point scale) for each of the eight questions are presented separately for males and females in Table 1.

The results were also analyzed by means of an analysis of variance classified by sex of rater, style of garment, and type of crime. The summary of this analysis for each of the eight questions follows:

1. "Estimate the likelihood that this woman might be robbed (raped) compared with other women of the same age." All subjects rated sexy clothes as more strongly related to both robbery and rape than nonsexy clothes $[F(1,135)=14.1, p<.001]$.

2. "How likely is it that this woman might provoke a man into attempting robbery (rape)?' Sexy clothes were judged to be more likely to provoke both rape and robbery than were nonsexy clothes $[F(1,135)=14.04$, $p<.001]$.

3. "If this woman is robbed (raped), how much should she be held responsible for what happens to her?" Males indicated that the woman should be held responsible for either crime to a greater extent than did females $[F(1,135)$ $=3.85, p<.05]$. Both men and women rated the woman wearing sexy clothes to be more responsible for her assault than the woman wearing nonsexy clothes $[F(1,135)$ $=13.66, p<.001]$.

4. "If this woman is robbed (raped), how much should her attacker be held responsible?' Both male and female raters indicated that the attacker should be held less responsible when the victim is wearing sexy clothes than when wearing nonsexy clothes $[F(1,135)=6.36$, $p<.025]$.

5. "If this woman is robbed (raped), and if her attacker is arrested and convicted, how severely should he be punished?' Both males and females indicated that the as- sailant should be punished more severely for rape than for robbery $[F(1,135)=13.81, p<.001]$.

6. "How attractive do you consider this woman to be?" Both men and women raters judged the model wearing sexy clothes to be more attractive than the model wearing nonsexy clothes $[F(1,135)=11.91, p<.001]$.

7. "If you were acquainted with the woman in the picture, how much do you think you would like her?" The males in the study rated the model as more likable than did the females $[F(1,135)=20.36, p<.001]$.

8. "To what extent would most men find this woman's clothing to be sexually exciting?" Both males and females rated the sexy clothing as being more sexually exciting than the nonsexy clothing $[F(1,135)=38.78, p<.001]$, with no significant difference found between the male and female raters with respect to this judgment. An interaction was also found in that the males rated the nonsexy clothing as being sexually exciting to a significantly greater extent than did the female raters $[F(1,135)=12.73$, $p<.001]$.

The results of this study do not support the expectation that sexy clothes would be perceived as more likly to be related to rape than to robbery. Instead, male and female subjects consistently viewed the model wearing sexy clothes as being more likely to be either raped or robbed (Question 1), more likely to provoke either rape or robbery (Question 2), and more responsible for either attack (Question 3). Furthermore, men and women agreed that the attacker should be held less responsible when the model is wearing sexy clothes regardless of whether she is raped or robbed (Question 4).

These findings appear initially to be inconsistent with attribution theory (Kelley, 1971). Seligman et al. (1977) and Tieger (1981) found that females judged to be attractive are seen as more likly to be raped, whereas nonattractive females are seen as being more responsible if they are raped. No relationship was found in these studies between physical attractiveness and crimes other than rape. In the present study, the sexier female (also judged to be more attractive) is seen as more responsible for being either raped or robbed than her more conservative counterpart. The apparent contradiction between the two sets

Table 1

Mean Ratings on a 5-Point Scale for Eight Questions Based Upon a Model Wearing Either Sexy or Nonsexy Clothing and Presented Either as a Hypothetical Robbery Victim or as a Rape Victim

\begin{tabular}{|c|c|c|c|c|c|c|c|c|}
\hline \multirow[b]{3}{*}{ Question } & \multicolumn{4}{|c|}{ Male Raters } & \multicolumn{4}{|c|}{ Female Raters } \\
\hline & \multicolumn{2}{|c|}{ Sexy Clothes } & \multicolumn{2}{|c|}{ Nonsexy Clothes } & \multicolumn{2}{|c|}{ Sexy Clothes } & \multicolumn{2}{|c|}{ Nonsexy Clothes } \\
\hline & Robbery & Rape & Robbery & Rape & Robbery & Rape & Robbery & Rape \\
\hline 1 & 3.08 & 3.70 & 2.92 & 3.00 & 3.68 & 3.78 & 3.08 & 2.95 \\
\hline 2 & 3.77 & 3.55 & 2.92 & 2.92 & 3.41 & 3.43 & 2.83 & 2.50 \\
\hline 3 & 3.69 & 3.18 & 4.21 & 4.50 & 4.05 & 4.00 & 4.54 & 4.36 \\
\hline 4 & 1.54 & 1.91 & 1.21 & 1.43 & 1.60 & 1.36 & 1.08 & 1.41 \\
\hline 5 & 4.08 & 4.18 & 4.21 & 4.86 & 3.77 & 4.66 & 4.08 & 4.36 \\
\hline 6 & 4.38 & 4.18 & 4.07 & 4.00 & 4.32 & 3.96 & 4.08 & 3.68 \\
\hline 7 & 3.86 & 4.00 & 3.85 & 4.07 & 3.23 & 3.22 & 3.45 & 3.27 \\
\hline 8 & 4.46 & 4.00 & 3.57 & 3.29 & 4.68 & 4.39 & 2.63 & 2.81 \\
\hline
\end{tabular}


of investigations disappears when it is considered that physical attractiveness is largely innate (i.e., involuntary) whereas clothing selection is under personal control. Females who elect to wear sexy clothes, therefore, are more likely to be seen as inviting attack.

The relationship between sexy clothing and robbery/rape supports the assumption that the culture views women who choose to be sexually attractive as being suitable objects for male aggression (e.g., Burt, 1980). Furthermore, this attitude seems to be held by both men and women (Questions 1, 2, 3, and 4). The extension of this stereotype to include nonsexual crimes is particularly curious and suggests that females who enhance their sexual appeal to males are viewed as somehow "asking for it." As noted above, the fact that no relationship was found between attractiveness and nonsexual crimes in earlier studies (Seligman et al., 1977; Tieger, 1981) is quite likely related to whether or not sexual attractiveness is perceived as being voluntary (clothes selection) or involuntary (physical attractiveness).

If male hostility toward attractive females is the root cause of aggression toward females, it is not revealed in ratings of likability (Question 7). The male subjects in this study judged the model in both clothing conditions to be more likable than did the females, with no difference in likability attributable to sexy or nonsexy clothing. Perhaps this outcome is related to the ambiguity of "likable" as a trait label. Presumably, a male might "like" a female in sexual terms but "dislike" some of her other characteristics, such as those related to trustworthiness, reliability, or honesty. Thus, male attitudes toward women may be interpretable as an admixture of attraction and hostility that requires further research for more precise delineation.
In summary, the present study seems to indicate that females wearing sexually oriented clothes are perceived by both men and women as being more vulnerable to victimization and more responsible for crimes committed against them than are women who dress more conservatively. Whether or not this perception is related to actual criminal behavior is not known. The fact that this stereotype applies to a nonsexual crime (robbery), as well as to rape, suggests that a general cultural bias is involved.

\section{REFERENCES}

BURT, M. R. (1980). Cultural myths and supports for rape. Journal of Personality \& Social Psychology, 38, 217-230.

Calhoun, L. G., Selby, J. W., \& Warring, L. J. (1976). Social perception of the victim's causal role in rape: An exploratory examination of four factors. Human Relations, 29, 517-526.

Feldman-Summers, S., \& Lindner, K. (1976). Perceptions of victims and defendants in criminal assault cases. Criminal Justice \& Behavior, 3, 135-149.

Jones, C., \& ARonson, E. (1973). Attribution of fault to a rape victim as a function of respectability of the victim. Journal of Personality \& Social Psychology, 3, 415-419.

Kelley, H. (1971). Attribution in social interaction. Morristown, NJ: General Learning Press.

Malamuth, W. M. (1986). Predictors of naturalistic sexual aggression. Journal of Personality \& Social Psychology, 50, 953-962.

National Crime Survey (1984). Criminal victimization in the U.S.: 1982 (final report) (Report No. NCJ-92820). Washington, D.C.: U.S. Government Printing Office.

Seligman, C., Brickman, J., \& Koulack, D. (1977). Rape and physical attractiveness: Assigning responsibility to victims. Journal of Personality, 45, 554-563.

Smith, R. E., Keating, J. P., Hester, R. K., \& Mitchell, H. E. (1976). Role and justice considerations in the attribution of responsibility to a rape victim. Journal of Research in Personality, 10, 346-357.

TIEGER, T. (1981). Self-rated likelihood of raping and the social perception of rape. Journal of Research in Personality, 15, 147-158. 